\title{
Surface Nanofeatures Induced by High-Energy Heavy Ions Irradiation
}

\author{
A. García-Bórquez ${ }^{a *}$, C. Camacho-Olguín ${ }^{a}$, \\ L. Herrera-Colín ${ }^{a}$, G. Rueda-Morales ${ }^{a}$ \\ AND W. KESTERNICH ${ }^{b}$ \\ ${ }^{a}$ ESFM-IPN, 07738 México D.F., Mexico \\ ${ }^{b}$ IFF-FZ Jülich, Germany
}

\begin{abstract}
During neutron, ions or electron irradiation of materials, the surface morphology can be microroughened in different forms. Using a tandem accelerator with high current capability, $3.66 \mathrm{MeV} \mathrm{Ni}$ and $\mathrm{Al}$ ions were implanted into $\mathrm{Ni}-22$ at $\% \mathrm{Si}$ alloy at $650^{\circ} \mathrm{C}$ and into $\alpha-\mathrm{Al}_{2} \mathrm{O}_{3}$ at $1000^{\circ} \mathrm{C}$, respectively. Scanning electron microscopy observation revealed surface nanofeatures induced by the irradiations. On the $\mathrm{Ni}-\mathrm{Si}$ alloy, long parallel channels are formed having a periodicity near to $2 \mu \mathrm{m}$ and a mean depth of $30 \mathrm{~nm}$ (atomic force microscopy measurements). On $\alpha-\mathrm{Al}_{2} \mathrm{O}_{3}$ nanopyramides with around $50 \mathrm{~nm}$ basis length and similar height were detected on some grains forming periodic chains. We assume that preferential sputtering produced both induced surface features.
\end{abstract}

PACS numbers: 96.35.Gt, 34.50.Dy

\section{Introduction}

Understanding surface microerosion in materials caused by particle bombardments is important for near surface studies on radiation damage of materials. It is further of high interest in studies using particle bombardment as means of analytical techniques such as the Auger spectroscopy, or the Rutherford backscattering. A new, exciting area, which is recently opening up, is the controlled production of surface nanofeatures and their correlation with surface property changes. Special interest began about ten years ago in the quantum confinement effects studied in objects of nanometric size [1-3], and also in Ni-based nanostructures [4].

With respect to $\mathrm{Ni}-\mathrm{Si}$ alloys, no reports were found, relating to radiation induced surface nanofeatures. Tanaka et al. reported [5] on effects at the surface area surrounding the area bombarded by a $25 \mathrm{keV} \mathrm{Ga}{ }^{+}$-focused ion beam on $\mathrm{Ni}_{2} \mathrm{Si} / \mathrm{Si}$ thin films, but did not report on the changes within the irradiated area.

*corresponding author; e-mail: borquez@esfm.ipn.mx 
Most of the works on irradiated alumina up to now have reported on bulk changes such as macroscopic swelling, vacancy formation [6, 7], phase transformation [8], crystallization [9], amorphization [10], ion track formation, ionizing effects [11], etc. There is only very scarce information concerning the surface changes caused by irradiation with energetic particles. Nakao et al. [9] have shown atomic force microscopy (AFM) images on alumina films before and after $1.5 \times 10^{17} \mathrm{Si}^{+} / \mathrm{cm}^{2}$ implantation, revealing granular features caused by the irradiation. Auciello and Kelly [12] describe pyramid as termed, regular and crystalline feature forming on high sputter yield materials, such as $\mathrm{Cu}, \mathrm{Au}, \mathrm{Ag}, \mathrm{Al}$, and $\mathrm{Pb}[12]$. A more recent report by Skuratov et al. [13, 14] describes nanofeatures, which were induced by $245-710 \mathrm{MeV}$ Bi and $\mathrm{Kr}$ ions, as hillock-like defects.

\section{Experimental}

Using a high intensity ion beam tandem accelerator, $3.66 \mathrm{MeV} \mathrm{Ni}$ and $\mathrm{Al}$ ions were implanted in a $\mathrm{Ni}-22 \mathrm{at} \% \mathrm{Si}$ alloy at $650^{\circ} \mathrm{C}$ and in $\alpha-\mathrm{Al}_{2} \mathrm{O}_{3}$ at $1000^{\circ} \mathrm{C}$, respectively. The respective specimen temperatures were achieved by resistance heating in the first case, and by radiation with a halogen lamp, in the second case. The temperatures were held constant within $10^{\circ} \mathrm{C}$ using an infrared pyrometer focused (1 $\mathrm{mm}$ in diameter) at the middle of the irradiated area $(6 \mathrm{~mm}$ in diameter). All experiments were carried out under a $10^{-7}$ mbar pressure [15]. The samples were irradiated with ion fluences in the range of $10^{17}-10^{18}$ ions $/ \mathrm{cm}^{2}$, up to extremely high dose: $100 \mathrm{dpa}$ for $\mathrm{NiSi}$ and $250 \mathrm{dpa}$ for $\alpha-\mathrm{Al}_{2} \mathrm{O}_{3}$. To study the radiation-induced features (RIF) at the surface of the studied materials, several surface techniques were employed. In particular, direct observation using scanning electron microscopy (SEM) and atomic force microscopy (AFM) were carried out. For the SEM measurements, quite different conditions were necessary to visualise the RIF at $\mathrm{Ni}-\mathrm{Si}$ and $\alpha-\mathrm{Al}_{2} \mathrm{O}_{3}$. For $\mathrm{Ni}-22 \mathrm{at} \% \mathrm{Si}$, long work distance (WD) and high accelerating voltage, i.e. $12-14 \mathrm{~mm}$ and $20 \mathrm{kV}$, respectively, were used to discern the presence of channels. Whereas for $\alpha-\mathrm{Al}_{2} \mathrm{O}_{3}$ very short WD and low accelerating voltage, i.e. $2 \mathrm{~mm}$ and $1 \mathrm{kV}$, respectively, were very successful to obtain high resolution without charging effect (no conductive recovering was necessary). In AFM, a standard cantilever working with $0.05 \mathrm{~N} / \mathrm{m}, 22 \mathrm{kHz}$ and, a $3 \mu \mathrm{m}-35^{\circ}$ pyramidal tip, were used in a non-contact mode.

\section{Results}

SEM observation gives evidence for surface nanofeatures induced by the ion irradiation at fluences between $10^{17}-10^{18}$ ions $/ \mathrm{cm}^{2}$. On the surfaces of the $\mathrm{Ni}-$ 22at\%Si alloy, long parallel channels (Figs. 1a, b) are formed having a periodicity near to $\lambda=2 \mu \mathrm{m}$ and a mean depth of $30 \mathrm{~nm}$ as measured by AFM (Fig. 1c). On the surface of $\alpha-\mathrm{Al}_{2} \mathrm{O}_{3}$, nanopyramids, with around $50 \mathrm{~nm}$ basis length and similar height were detected on some grains. The pyramids tend to be arranged in periodic chains (Fig. 2). 

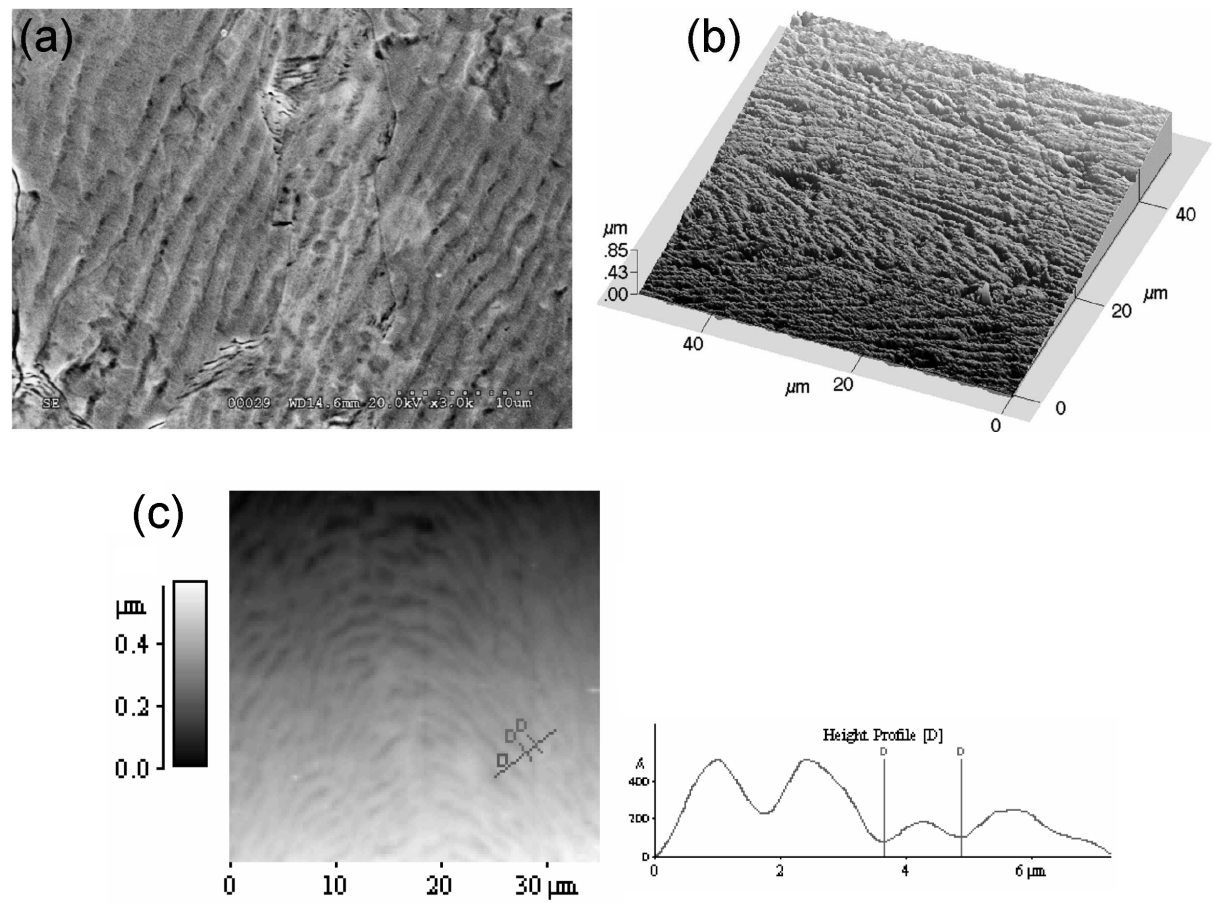

Fig. 1. (a) SEM micrograph showing a groove pattern preferential sputter to a fluence of $10^{17}-10^{18} \mathrm{Ni}$ ions $/ \mathrm{cm}^{2}$ at $650^{\circ} \mathrm{C}$ from a mirror polished $\mathrm{Ni}-22$ at\% $\mathrm{Si}$ surface. (b) AFM 3-dimensional image of a groove pattern. (c) Image and diagram as an AFM measurement of periodicity is taken. Similar process is followed by depth measurement.

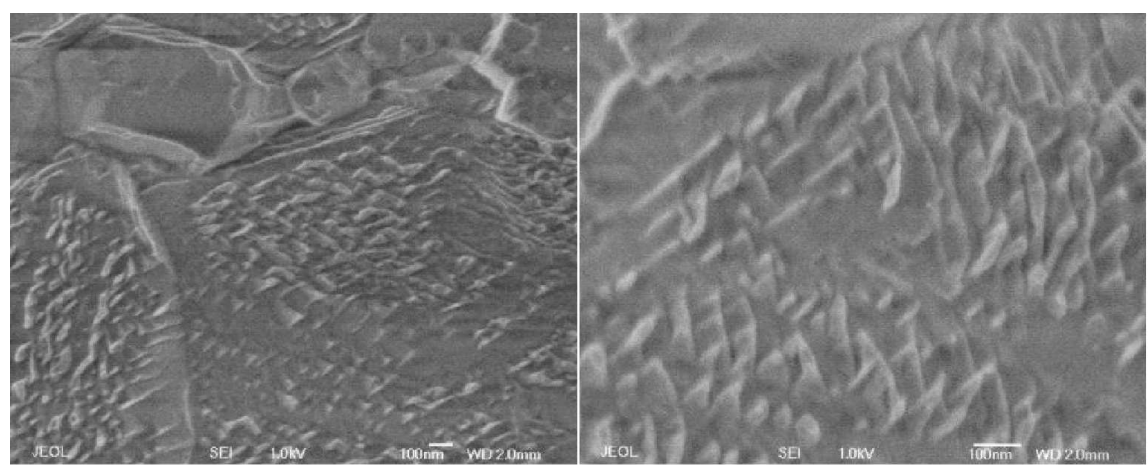

Fig. 2. SEM micrographs showing details of the nanopyramids (50 nm) after $250 \mathrm{dpa}$ dose induced by $3.66 \mathrm{MeV} \mathrm{Al}$ ions at $1000^{\circ} \mathrm{C}$.

\section{Discussion}

The Ni-22at\%Si alloy presents lamellar structure before irradiation as expected for an eutectic composition and confirmed by metallographic test. X-ray 
diffraction (XRD) revealed the lamella to consist of disordered $\mathrm{Ni}-\mathrm{Si}$ and $\mathrm{Ni}_{3} \mathrm{Si}$ phases, respectively. We assume that the $3.66 \mathrm{MeV} \mathrm{Ni}$ ion bombardment produces channels by sputtering preferentially one of the two phases, presumably the disordered Ni-Si phase. Supporting these considerations is the fact that this phase has more abundance of the weak $\mathrm{Ni}-\mathrm{Ni}$ metallic bonds, because it is richer in $\mathrm{Ni}$ than the ordered $\mathrm{Ni}_{3} \mathrm{Si}$ phase. Similar periodical $(\lambda=700 \mathrm{~nm})$ features, forming subtle ripples on (111) surfaces in Ge during etching by $5 \mathrm{keV}$ Xe ions, have previously been reported [16]. It was concluded by the authors that the curvature dependence of the sputtering yield underestimates the observed periodicity and that the possibility of preferential sputtering of step-edge atoms as a function of step orientation need to be considered.

The sharp, faceted pyramids and their periodic arrays, induced by $3.66 \mathrm{MeV}$ $\mathrm{Al}$ ion bombardment of $\alpha-\mathrm{Al}_{2} \mathrm{O}_{3}$, is thought to be due to crystallographic preferential sputtering (CPS) taking place during irradiation. Features similar in form were reported as sputter cones formed on $\mathrm{Cu}$ surfaces by $1 \mathrm{keV} \mathrm{Ar}{ }^{+}$bombardment at $300^{\circ} \mathrm{C}$ at a fluence of $2 \times 10^{18}$ ions $/ \mathrm{cm}^{2}$, but they had around $700 \mathrm{~nm}$ basis length and $1 \mu \mathrm{m}$ height and were formed as result of an impurity-initiated mechanism owing to the presence of $\mathrm{W}$ surface impurities [17]. Features similar in size were reported as hillocks formed on the surfaces of $\alpha-\mathrm{Al}_{2} \mathrm{O}_{3}$ and $\mathrm{MgO}$ irradiated with high energy $\mathrm{Kr}$ and $\mathrm{Bi}$ ions, and have been suspected to form by plastic deformation due to defects created by the Coulomb explosion mechanism in the target subsurface layer $[13,14]$.

\section{Conclusions}

1. Both observed grooves at $\mathrm{Ni}-22$ at\% $\%$ alloy and nanopyramids at $\alpha-\mathrm{Al}_{2} \mathrm{O}_{3}$ are radiation-induced features.

2. Our RIFs were produced by preferential sputtering (PS) by two different mechanisms not reported up today in these materials.

3. PS has left grooved patterns on the $\mathrm{Ni}-22 \mathrm{at} \% \mathrm{Si}$ surface by eroding faster one of the two-phases forming the eutectic crystallisation structure.

4. The long parallel channels forming the grooved patterns have a periodicity near to 2 microns and a mean depth of $30 \mathrm{~nm}$.

5. In $\alpha-\mathrm{Al}_{2} \mathrm{O}_{3}$, sharp faceted pyramids sometimes aligned in periodic chains, have been formed by CPS.

6. The nanopyramids show projected basis, height and top angle between 40-100 nm, 60-90 nm and 55-75', respectively.

\section{Acknowledgments}

The authors are grateful for the Forschungszentrum-Jülich irradiation facilities. A. García-Bórquez thanks also the COFAA support. 


\section{References}

[1] K.F. Braun, K.H. Rieder, Phys. Rev. Lett. 88, 096801 (2002).

[2] S.M. Pons, J.Y. Veuillen, Phys. Rev. B 64, 193408 (2001).

[3] F.M. Leisble, Surf. Sci. 514, 33 (2002).

[4] J.Y. Veuillen, P. Mallet, L. Magaud, S. Pons, J. Phys., Condens. Matter 15, S2547 (2003)

[5] M. Tanaka, K. Furuya, T. Saito, MRS Symp. Proc. 438, 313 (1996).

[6] R.A. Youngman, T.E. Mitchell, F.W. Clinard, G.F. Hurley, J. Mater. Res. 6, 2178 (1991).

[7] G.V. Kornich, G. Betz, A.I. Bazhin, Tech. Phys. Lett. 26, 445 (2000).

[8] C. Kinoshita, Y. Tomokiyo, K. Nakai, Ultramicroscospy 56, 216 (1994).

[9] S. Nakao, P. Jin, G. Xu, M. Ikeyama, Y. Miyagawa, J. Crystal Growth 237-239, $580(2002)$.

[10] C.J. McHargue, P.S. Sklad, J.C. McCallum, C.W. White, Mater. Res. Soc. Symp. Proc. 157, 555 (1990).

[11] S.J. Zinkle, V.A. Skuratov, D.T. Hoelzer, Nucl. Instrum. Methods Phys. Res. B 191, 758 (2002).

[12] O. Auciello, R. Kelly, Ion Bombardment Modification of Surfaces, Elsevier, New York 1984, p. 301.

[13] V.A. Skuratov, S.J. Zinkle, A.E. Efimov, K. Havancsak, Nucl. Instrum. Methods Phys. Res. B 203, 136 (2003).

[14] V.A. Skuratov, S.J. Zinkle, A.E. Efimov, K. Havancsak, Surf. Coat. Technol. 196, 56 (2005)

[15] A. García-Bórquez, Ph.D. thesis, Instituto Politécnico Nacional, México 1994, p. 20 .

[16] G.C. David, R.S. Averback, Phys. Rev. B 67, 045404 (2003).

[17] R.S. Robinson, S.M. Rossnagel, J. Vac. Sci. Technol. 21, 790 (1982). 